\title{
Synthesis and Properties of Unsymmetry Diarylethene 1-[2-methyl-5- trimethylsilacetenyl-3-thienyl]-2-[2-Cyanophenyl] Perfluorocyclopentene
}

\author{
Shengzu Qu, Ben Chen, Lili Li, Chunhong Zheng* and Shouzhi Pu \\ Jiangxi Key Laboratory of Organic Chemistry \\ Jiangxi Science and Technology Normal University \\ Nanchang 330013, P.R.China \\ e-mail:pushouzhi@tsinghua.org.cn
}

\begin{abstract}
A new unsymmetrical photochromic diarylethene 1[2-methyl-5- trimethylsilacetenyl-3-thienyl]-2-[2-Cyanophenyl] perfluorocyclopentene (10) were synthesized. Under alternating irradiation with $\mathrm{UV}$ and visible light, the compounds showed favorable photochromism in hexane. The product changing from colorless to orange after irradiation with $297 \mathrm{~nm}$ UV light, and the product has been characterized by UV/Vis spectrophotometry, Fluorescence spectrophotometry. The cyclization processes of compound (1c) belong to the zero order reaction.
\end{abstract}

Keywords-diarylethene; kinetics; photochromic

\section{INTRODUCTION}

Photochromic compounds have been extensively studied for optoelectronic devices such as for photoswitches, fullcolour displays, and optical data storage [1-3]. Among such compounds, diarylethenes that bear thiophene rings have received the most attention due to the high thermal stability fatigue resistance, notable, and rapid response [4]. Photochromic diarylethenes undergo reversible photoisomerization between two isomers with different absorption spectra upon irradiation with light of appropriate wavelength [5], which makes them good candidates for realizing smart optical modulation.

Up to now, a large number of publications concerning diarylethene derivatives with different aryl moieties, such as benzothiophene [6], thiophene [7], thiazole [8], furan [9], and pyrrole [10], pyrazole [11], have been reported. In this work, a new photochromic diarylethene compound, 1-[2methyl-5-(4-pentane phenyl)-3-thienyl]-2-[2-phenyl] perfluorocyclopentene (10) was synthesized, which fluorescence, photochromic reactivity were investigated in detail. The photochromic reaction of diarylethene 10 is shown in Scheme 1.

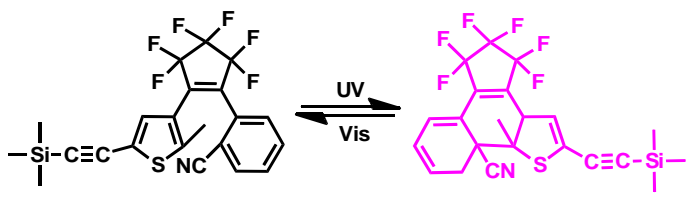

10 1c

Scheme 1. Photochromism of diarylethene 10.

\section{EXPERIMENTS}

\section{A. Synthesis of diarylethene 10.}

The synthetic route of this photochromic compound was shown in Scheme 2. It was synthesized according to the similar procedure of [12]. The structure of compound 1o was confirmed by $1 \mathrm{H}$ NMR (400 MHz, CDCl3): $\delta 1.80(\mathrm{~m}, 3 \mathrm{H},-$ CH3), 6.93 (s, 1H, thienyl-H), 7.37 (m, 2H, phenyl-H), 7.49 (m, 2H, phenyl-H).

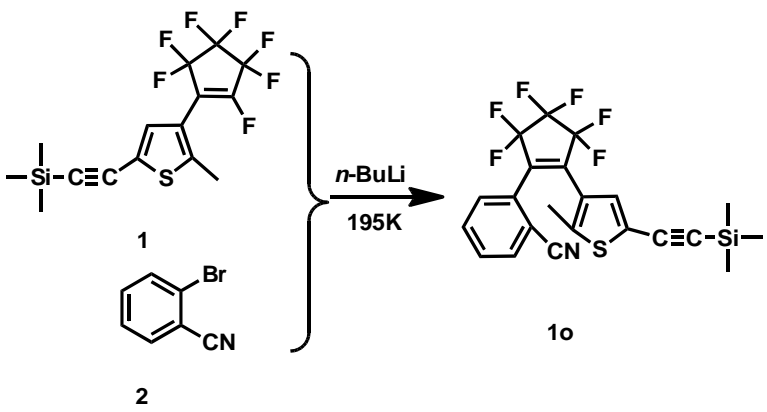

Scheme 2. Synthetic route for 10 .

\section{Results AND Discussion}

\section{A. Photochromism of diarylethene 10.}

The changes in the absorption spectra of diarylethene 10 , which were induced by photoirradiation at room temperature in hexane $\left(2.0 \times 10^{-5} \mathrm{~mol} / \mathrm{L}\right)$ are shown in Figure 1. After UV irradiation, diarylethene 10 turned from colorless to orange. Then, the orange colored solution reverted to colorless upon irradiation with visible light $(\lambda>500 \mathrm{~nm})$ ,which indicated that $1 \mathrm{c}$ returned to the initial state 10 . The maximum absorption of open-ring isomer 10 was observed at $273 \mathrm{~nm}$ and the new absorption band appeared at $545 \mathrm{~nm}$, which can be assignable to the generation of $1 \mathrm{c}$. 


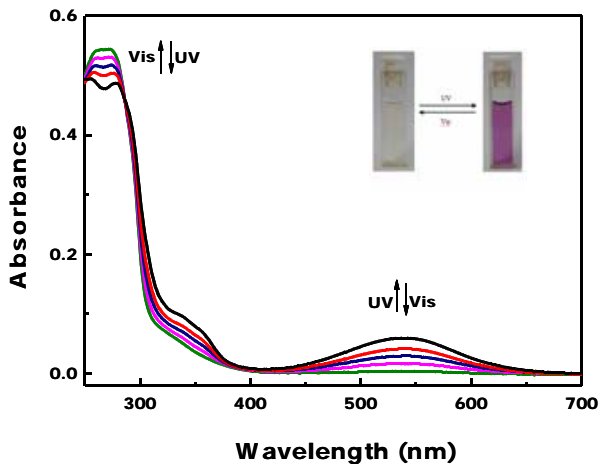

Figure 1. Absorption spectral and color change of compound 1o in hexane.

\section{B. Photochromic reaction kinetics in hexane.}

The photochromic cyclization/cycloreversion kinetics of $1 o$ in hexane were determined by UV/Vis spectra upon alternating irradiation with UV and appropriate wavelength visible light at room temperature. The cyclization and cycloreversion curves of compound 1 are shown in Figure $2 \mathrm{~A}$. It can be seen that the cyclization processes of compound 1o belong to the zeroth order reaction when openring isomer changed to closed-ring isomer. At the same time, during the cycloreversion of $1 \mathrm{c}$, the relationship between $\log$ ( Abs ) and exposal time also behave perfect linearity, as shown in Figure 2B, indicating that the cycloreversion process belong to the first order reaction. So all $\mathrm{k}$ of cyclization/cycloreversion process of diarylethene 1c can be easily obtained in solution, respectively.
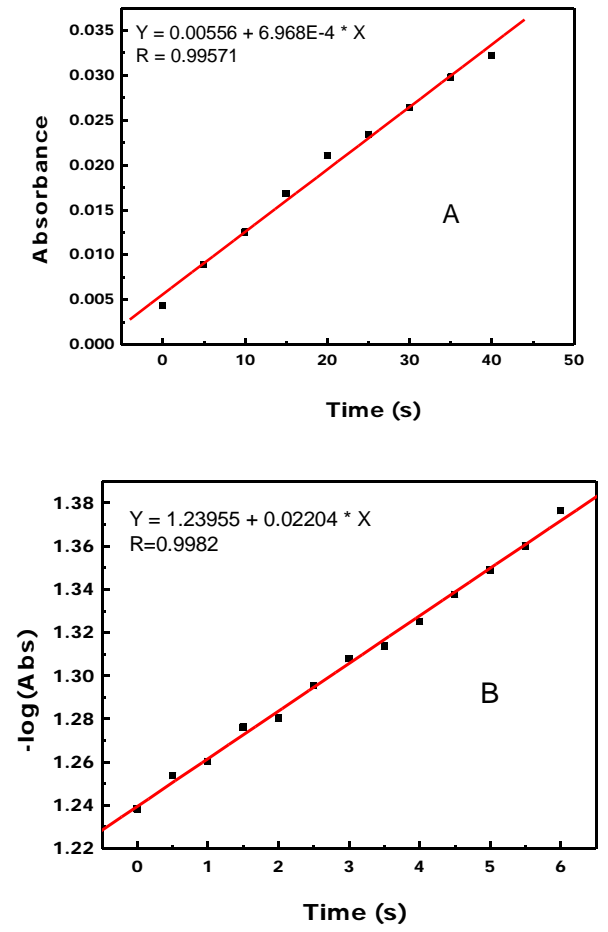

(C) 2015. The authors - Published by Atlantis Press 0094
Figure 2. The cyclization/cycloreversion kinetics of compound $l$ in hexane.

\section{Fluorescence of diarylethene 10.}

Additionally, the fluorescence intensity of diarylethene 1o ( $\left.2.0 \times 10^{-5} \mathrm{~mol} \mathrm{~L}^{-1}\right)$ decreased along with the photochromism because the photocyclization reaction produced the non-fluorescent closed-ring form. The back irradiation by appropriate wavelength visible light regenerated its open-ring isomer and recovered the original emission intensity. The emission intensity of diarylethene 10 was quenched $73 \%$ at the photostationary state in dichloromethane solution. This phenomenon indicated that cyclization reaction is incomplete and the existence of parallel conformation may be the main cause for the change in fluorescence intensity. The reversible changes of the emission intensity of diarylethene 10 are useful for application as the fluorescence switches [13].

\section{SUMMARY}

We synthesize a new unsymmetrical photochromic diarylethene and investigate its photochromic properties. Besides, the cyclization and cycloreversion processes of the compound were determined to be the zeroth and first order reaction by UV/Vis spectra, respectively. All the results will contribute to the further investigation of the diarylethene.

\section{ACKNOWLEDGMENT}

The authors are grateful for the financial support from the National Natural Science Foundation of China (21362013, 51373072)

\section{REFERENCES}

[1] M. Irie, "Diarylethenes for memories and switches," Chemical Reviews. vol. 100, 2000, pp. 1685-1716, Doi: 10.1021/cr980069d.

[2] H. Tian, and Y.Songjie, "Recent progresses on diarylethene based photochromic switches," Chemical Society Reviews., vol. 33, 2004, pp.85-97, Doi: 10.1039/B302356G.

[3] K. Matsuda, and M. Irie, "Diarylethene as a photoswitching unit," Journal of Photochemistry and Photobiology C: Photochemistry Reviews, vol. 5, 2004, pp. 169-182. doi: 10.1016/j.

[4] R.J. Wang, "New photochromic 1, 2-diarylperfluorocyclopentenes bearing unsymmetrical six-membered aryl units," Tetrahedron Letters, vol. 53, 2012, pp. 320-324. Doi: doi:10.1016/j.tetlet.2011.11.035.

[5] K. Seiya, and M. Irie, "Synthesis and Photochromism of Diarylethenes with Isopropyl Groups at the Reactive Carbons and Long. PI.Conjugated Heteroaryl Groups," Chemistry Letters, vol 32, 2003, pp. 1078-1079, doi:10.1246/cl.2003.1078.

[6] Y. Yasushi, S. Hidenori, T. Yutaka, et al., "Diastereoselective photochromism of a bisbenzothienylethene governed by steric as well as electronic interactions," Journal of the American Chemical Society., vol. 125, 2003, pp. 7194-7195. doi:10.1021/ja029535d.

[7] M. Masakazu, K. Seiya, and M. Irie, "Multicolor photochromism of two-and three-component diarylethene crystals," Journal of the American Chemical Society., vol. 125,2003, pp. 11080-11087. doi:10.1021/ja035277o.

[8] K. Uchida, "Thermally irreversible photochromic systems. Reversible photocyclization of 1, 2-bis (thiazolyl) perfluorocyclopentenes," Tetrahedron, vol. 54, 1998, pp. 6627-6638. doi:10.1016/ S0040-4020(98)00330-5. 
[9] X.H. Deng, and S. Lanny, "A contribution to the design of molecular switches: Novel acid-mediated ring-closing-photochemical ringopening of 2, 3-bis (heteroaryl) quinones (heteroaryl= thienyl, furanyl, pyrrolyl)," Journal of the American Chemical Society., vol 123, 2001, pp. 7703-7704.doi:10.1021/ja0106220.

[10] S.Z. Pu, "Efficient synthesis and properties of isomeric photochromic diarylethenes having a pyrrole unit," Organic letters, vol. 9, 2007, pp. 2139-2142. Doi: 10.1021/ol070622q.

[11]T.S Yang, "Electron-donating methoxyl group position effect on properties of diarylethene derivatives having a pyrazole unit,"
Canadian journal of chemistry, vol. 85, 2007, pp. 12-20. doi:10.1139/v06-182.

[12] Liu, Gang, "1, 2-Bis [5-(3, 5-difluorophenyl)-2-methyl-3-thienyl]-3, 3, 4, 4, 5, 5-hexafluorocyclopent-1-ene: a new photochromic diarylethene compound," Acta Crystallographica Section E: Structure Reports Online, vol 62, 2006, pp. 2877-2879. doi: $10.1107 / \mathrm{S} 1600536806022306$.

[13]Q. F. Luo, "Recent progress on photochromic diarylethene polymers," Polymer Chemistry, vol. 11, 2011, pp. 2435-2443. doi:10.1039/C1PY00167A. 